\title{
Laboratory Study on Properties of Diatomite and Basalt Fiber Compound Modified Asphalt Mastic
}

\author{
Yongchun Cheng, ${ }^{1}$ Chunfeng Zhu, ${ }^{1,2}$ Guojin Tan, ${ }^{1}$ Zehua Lv, \\ Jinsheng Yang, ${ }^{1}$ and Jiansheng $\mathrm{Ma}^{1}$ \\ ${ }^{1}$ College of Transportation, Jilin University, Changchun, Jilin 130025, China \\ ${ }^{2}$ Jilin Communications Polytechnic, Changchun, Jilin 130012, China \\ Correspondence should be addressed to Guojin Tan; tgj@jlu.edu.cn
}

Received 23 May 2017; Accepted 2 July 2017; Published 1 August 2017

Academic Editor: Peter Majewski

Copyright (C) 2017 Yongchun Cheng et al. This is an open access article distributed under the Creative Commons Attribution License, which permits unrestricted use, distribution, and reproduction in any medium, provided the original work is properly cited.

\begin{abstract}
In order to improve the performance of asphalt mastic, some researchers have added diatomite or basalt fiber as a modifier to the asphalt mastic, and the results show that some properties of the asphalt mastic were improved. For the simultaneous addition of diatomite and basalt fiber, two kinds of modifier, compound modified asphalt mastic had not been reported; in this paper, thirteen groups of diatomite and basalt fiber (DBFCMAM) compound modified asphalt mastic with different content were prepared to study the performance. Softening point, cone penetration, viscosity, and DSR tests were conducted, for the high temperature performance evaluation of DBFCMAM, whereas force ductility and BBR tests were used in the low temperature performance study of the DBFCMAM. The results demonstrated that the high temperature performance of DBFCMAM was increased; moreover, the low temperature performance of DBFCMAM improved by diatomite and basalt fiber according to the results of the force ductility test; however, the conclusion of the BBR test data was inconsistent with the force ductility test. In summary, the high temperature and low temperature properties of DBFCMAM had been improved.
\end{abstract}

\section{Introduction}

Compared to the cement concrete pavement, the asphalt pavement has the advantages of low cost, low noise, safety, and comfortable driving, as well as recycling. Therefore, the asphalt mixture is widely used in road construction. Approximately $90 \%$ of the roads in China are constructed by asphalt mixture $[1,2]$. Asphalt mastic is an important part of the asphalt mixture. The corresponding performance directly affects the performance of the asphalt mixture [3, 4]. Asphalt is a typical viscoelastic material, which is characterized by flow state at high temperature and brittle hard state at low temperature. It causes the asphalt pavement to produce rutting and cracks [5]. The modified asphalt is used to improve the properties of high temperature, low temperature, and fatigue resistance. This is an important means to prolong the service life of asphalt pavement. At present, the common asphalt modifier can be divided into the polymer-modified material and the inorganic modified material [6-14]. By the inorganic modified material utilization such as diatomite and basalt fiber as the modifier, not only the asphalt performance could be enhanced, but also the polymer modifier pollution to the environment could be avoided. Therefore, researchers have gradually paid attention to the utilization of inorganic modified materials [15-26].

Diatomite is a type of material with light weight, high porosity, low density, high surface absorption rate, high reserves, and low cost. Due to these characteristics, it was utilized in modified asphalt mastics and modified asphalt mixtures [15]. Cong et al. [16] studied the diatomite modified asphalt mastic. The results indicated that no chemical reaction between diatomite and asphalt occurred. The viscosity and the complex modulus of the diatomite modified asphalt mastic were increased as the diatomite content increased at high temperature. But the diatomite could not improve the asphalt performance at the low temperature. Bao [17] 
studied the basic properties of the diatomite modified asphalt mastic and concluded that as the diatomite content increased, the penetration and the ductility of modified asphalt mastic decreased, whereas the softening point increased. Wang [18] studied the antiaging micromechanism and mechanical properties of the diatomite asphalt mastic. The results demonstrated that diatomite significantly improved the aging of the asphalt mastic compared to the mineral powders. The asphalt mastic had optimum mechanical properties at high temperature when diatomite replacement rate was $75 \%$. Cheng et al. [8] reported that the improvement of diatomite on asphalt mastic was more significant than lime, hydrated lime, and fly ash under moderate temperature and high temperature. Li et al. [19] studied the properties of diatomite modified asphalt mastic and the corresponding asphalt mixtures. The results demonstrated that the flexural strength and the flexural strain of diatomite modified asphalt mixture were lower than the reference material at low temperature. Zhu et al. [20] evaluated the high temperature stability and low temperature crack resistance of diatomite modified asphalt mixture in the laboratory. The results showed that diatomite significantly improved the rutting resistance of the asphalt mixture, whereas when the flexural stiffness modulus increased, the low temperature performance decreased. The aforementioned results demonstrated that the diatomite addition contributed to the high temperature stability and antiaging performance improvement of the asphalt mastic and mixture, whereas it was not conducive to the ductility of the asphalt mastic at low temperature. The low temperature stiffness modulus increased and the flexibility decreased in this condition.

The basalt fiber is a type of high performance fiber, which is made of basalt rock. Due to the corresponding high strength and high resistance to water, acid, and alkali, along with the applicability to a wide range of temperatures and the good performance of durability, basalt fiber caused widespread concern in the research community [21]. In recent decades, basalt fiber has been widely utilized as a reinforcing modifier for the asphalt mastic and asphalt mixture performance [22-26]. Rong et al. [22] added the chopped basalt fiber into the asphalt mixture discovering that the fatigue durability of the mixture increased significantly. Morova [23] discovered that the $0.5 \%$ basalt fiber addition could significantly increase the high temperature stability of the asphalt mixture. Zheng et al. [24] studied the fatigue property of asphalt mixtures under complicated environments (low temperature bending performance, chloride penetration, freezing-thawing cycle, and corresponding coupling effect). The results indicated that the low temperature bending performance and the fatigue property of the asphalt mixtures under complicated environments could be highly improved by the basalt fiber addition. Wang et al. [12] conducted both the direct tension test and a newly developed fatigue test for the basalt fiber modified asphalt. The direct tension test results demonstrated that, at an appropriate content, the tensile strength of the asphalt mastic improved along with the basalt fiber utilization. The fatigue test results indicated that the fatigue life of asphalt mastic was significantly improved by basalt fibers. Xiong et al. [25] discovered that the high temperature performance of asphalt mastic could be improved by the basalt fiber addition. Liu et al. [26] studied the various effects of three types of fibers on the low temperature performance of both asphalt mastic and asphalt mixture, by the BBR test and low temperature beam bending tests. The results displayed that at $-10^{\circ} \mathrm{C}$, compared to the neat asphalt mastic, basalt fiber modified asphalt mastic had lower creep stiffness $(S)$ and higher creep rate $(m)$ value, the low temperature performance of basalt fiber modified asphalt mastic was improved, and the low temperature crack resistance of basalt fiber asphalt mixture was also improved. $\mathrm{Gu}$ et al. [13] studied rheological behavior of basalt fiber reinforced asphalt mastic by dynamic shear rheological tests and repeated creep tests, discovering that basalt fiber had high absorption rate, high tensile strength, high elastic modulus, and high temperature stability. It could be observed that basalt fiber contributed to the crack resistance improvement of asphalt mastic at low temperature and the deformation resistance at high temperature, respectively. In summary, it could be observed that the performance of asphalt mastic could be improved by the addition of diatomite or basalt fiber. However, certain deficiencies still exist. The low temperature performance of asphalt mastic was decreased by diatomite addition, which could be increased by the addition of diatomite and basalt fiber, simultaneously.

In this paper, the thirteen different groups of diatomite and basalt fiber compound modified asphalt mastic (DBFCMAM) were studied. The softening point test, cone penetration test, the viscosity test, and the DSR test were applied for the high temperature performance evaluation of DBFCMAM; the force ductility test and the BBR test were utilized in the low temperature performance study of DBFCMAM. According to the results, the effects on the properties of asphalt mastic by diatomite and basalt fiber addition were analyzed, providing reference for the diatomite and basalt fiber in asphalt pavement applications.

\section{Experimental}

2.1. Materials. The utilized asphalt AH-90 in this paper was supplied by Panjin Petrochemical Industry, located in Liaoning Province of China. The physical indicators of the neat asphalt are presented in Table 1.

The diatomite originated from the Changbai Mountain area of Jilin Province. The physical properties and particle size distribution are presented in Table 2. The basalt fiber was supplied from the Jiuxin Basalt Industry Co., Ltd, in Jilin Province, whereas the technical properties are presented in Table 3.

2.2. Preparation of DBFCMAM. According to the reference method for the preparation of diatomite or fiber modified asphalt mastics $[9,13,16,25-28]$, the optimal content of diatomite was about $15 \%$ or that of basalt fiber is about $3 \%$. Thus, in order to comprehensively analyze the performance of compound modified asphalt mastic with the change of the content of diatomite and basalt fiber, the contents of diatomite $5 \%, 10 \%$, and $15 \%$ and the contents of basalt fiber $1 \%, 2 \%$, $3 \%$, and $4 \%$ were adopted and comprehensive trail design of 
TABLE 1: Physical properties of neat asphalt.

\begin{tabular}{lcc}
\hline Property & Value & Standard value \\
\hline Density $\left(15^{\circ} \mathrm{C}, \mathrm{g} / \mathrm{cm}^{3}\right)$ & 1.016 & - \\
Penetration $\left(25^{\circ} \mathrm{C}, 0.1 \mathrm{~mm}\right)$ & 91.8 & $80-100$ \\
Softening point $T_{\mathrm{R} \& \mathrm{~B}}\left({ }^{\circ} \mathrm{C}\right)$ & 46.9 & $\geq 45$ \\
Ductility $\left(25^{\circ} \mathrm{C}, \mathrm{cm}\right)$ & $>150$ & $\geq 100$ \\
Viscosity $\left(135^{\circ} \mathrm{C}, \mathrm{Pa} \cdot \mathrm{s}\right)$ & 306.9 & - \\
\hline \multicolumn{2}{c}{ After TFOT } \\
Mass loss $(\%)$ & 0.38 & $\leq \pm 0.8$ \\
Residual penetration ratio $\left(25^{\circ} \mathrm{C}, \%\right)$ & 73.3 & $\geq 57$ \\
Softening point $T_{\mathrm{R} \& \mathrm{~B}}\left({ }^{\circ} \mathrm{C}\right)$ & 49.6 & - \\
Ductility $\left(15^{\circ} \mathrm{C}, \mathrm{cm}\right)$ & $>120$ & $\geq 20$ \\
Viscosity $\left(135^{\circ} \mathrm{C}, \mathrm{Pa} \cdot \mathrm{s}\right)$ & 432.5 & - \\
\hline
\end{tabular}

TABle 2: Properties of diatomite.

\begin{tabular}{lcccc}
\hline Property & Color & $\mathrm{pH}$ & $\begin{array}{c}\text { Specific gravity } \\
\left(\mathrm{g} / \mathrm{cm}^{3}\right)\end{array}$ & $\begin{array}{c}\text { Bulk density } \\
\left(\mathrm{g} / \mathrm{cm}^{3}\right)\end{array}$ \\
\hline Value & $\begin{array}{c}\text { Off- } \\
\text { white }\end{array}$ & $7-8$ & $2.0-2.2$ & $0.34-0.41$ \\
\hline
\end{tabular}

TABle 3: Properties of basalt fiber (provided by manufacturer).

\begin{tabular}{lcc}
\hline Items & Value & Standard value \\
\hline Diameter $(\mu \mathrm{m})$ & $10-13$ & - \\
Length $(\mathrm{mm})$ & 6 & - \\
Water content $(\%)$ & 0.030 & $\leq 0.2$ \\
Combustible content $(\%)$ & 0.56 & - \\
Linear density (Tex) & 2398 & $2400 \pm 120$ \\
Breaking strength $(\mathrm{N} / \mathrm{Tex})$ & 0.55 & $\geq 0.40$ \\
Tensile strength $(\mathrm{MPa})$ & 2320 & $\geq 2000$ \\
Tensile modulus of elasticity $(\mathrm{GPa})$ & 86.3 & $\geq 85$ \\
Elongation at break (\%) & 2.84 & $\geq 2.5$ \\
\hline
\end{tabular}

diatomite and basalt fiber is performed. Finally we obtain 13 groups of different compound modified asphalt mastic in this paper. The contents of diatomite and basalt fiber were listed in Table 4.

The preparation of DBFCMAM was as the following process in this paper. Firstly, the neat asphalt diatomite and basalt fiber were separately placed in an oven at $150^{\circ} \mathrm{C}$ for $4 \mathrm{~h}$, which ensured the asphalt sufficient liquidity and that diatomite and basalt fiber reached the mixing temperature. Subsequently, the diatomite and basalt fiber were added in asphalt mastics at a certain proportion and mixed by a high-speed shear homogenizer (KRH-I, Shanghai Konmix Mechanical \& Electrical Equipment Technology Co. Ltd., China) with a heat preservation pot. The mixing temperature was $150^{\circ} \mathrm{C}$, the shearing speed rate was $5000 \mathrm{r} / \mathrm{min}$, and the mixing duration was $50 \mathrm{~min}$, so that the diatomite and basalt fiber could be evenly distributed within the asphalt mastics. Diatomite or basalt fiber content was calculated by weight of the neat asphalt. Due to different density values of the three materials, the compound modified asphalt mastic was placed following a period of time, diatomite and basalt fiber would

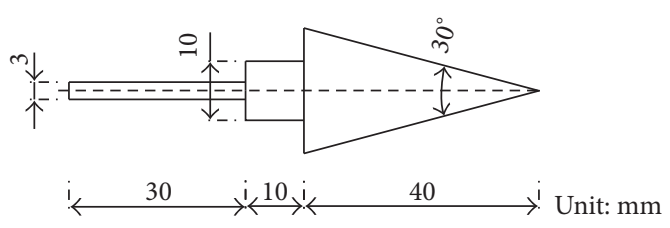

Figure 1: Cone structure size.

have a sink, and DBFCMAM should be mixed again prior to further utilization.

\subsection{Physical and Mechanical Properties from DBFCMAM Tests}

2.3.1. Cone Penetration Test. Due to diatomite and basalt fiber addition, the uniform system of the asphalt changed into hybrid dispersions. The content and particle size affected the corresponding performance of asphalt mastic; consequently the penetration test data were highly discrete. Through the study of Chen et al. [14, 25], the cone penetration test was utilized to measure the fluidity and shear strength of DBFCMAM in this paper.

In this paper, according to the test method for penetration of bituminous materials (ASTM D5/D5M-2013), the cone penetration test was designed for the measurements. The custom-made cone replaced the standard needle of the penetration instrument and the cone structure size is presented in Figure 1. Through the cone depth, the shear stress was calculated as the test index. The shear stress $\tau(\mathrm{kPa})$ of DBFCMAM could be calculated by the following equation:

$$
\tau=\frac{Q \cos ^{2}(\alpha / 2)}{\pi h^{2} \tan (\alpha / 2)}
$$

where $\tau$ is the shear stress $(\mathrm{kPa}), Q$ is the cone quality $(90.3 \mathrm{~g}$ ), $h$ is the sink depth $(0.1 \mathrm{~mm})$, and $\alpha$ is the cone angle $\left(30^{\circ}\right)$.

2.3.2. Softening Point Test. Softening point is widely utilized in the high temperature sensitivity evaluation of asphalt mastic [29]. Therefore the softening point test of DBFCMAM with various contents was executed by the method specified in ASTM D36 (ASTM D36/D36M-2014).

2.3.3. Force Ductility Test. In 1976, Anderson and Wiley introduced the force ductility test, followed by a high number of researchers that utilized this method to evaluate the tensile properties of asphalt [29-31]. The results [7, 8, 31, 32] reported that the force extension test was a reliable and effective method. In this paper, the low temperature tensile properties of DBFCMAM were evaluated by this method. According to the standards of EN13589 [33] and EN13703 [34], the maximum force $\left(F_{\max }\right)$, the stretched elongation $\left(D_{\mathrm{ON}}\right)$, and the deformation energy $(J)$ were used as the evaluation indexes. The maximum force $\left(F_{\max }\right)$ and the stretched elongation $\left(D_{\mathrm{ON}}\right)$ values were obtained by the experiment recording and the force-elongation curves were drawn, with the acquisition data obtained from the experiment recording. The deformation energy $(J)$ could be calculated from the area under the curve from $20 \mathrm{~mm}$ to $40 \mathrm{~mm}$ [34]. The test was 
TABLE 4: Contents of diatomite and basalt fiber.

\begin{tabular}{|c|c|c|c|c|c|c|c|c|c|c|c|c|c|}
\hline Test number & 1 & 2 & 3 & 4 & 5 & 6 & 7 & 8 & 9 & 10 & 11 & 12 & 13 \\
\hline Diatomite content (\%) & 0 & 5 & 5 & 5 & 5 & 7.5 & 7.5 & 7.5 & 7.5 & 10 & 10 & 10 & 10 \\
\hline Basalt fiber content $(\%)$ & 0 & 1 & 2 & 3 & 4 & 1 & 2 & 3 & 4 & 1 & 2 & 3 & 4 \\
\hline
\end{tabular}

executed by the same test mold for the elastic recovery test (ASTM D6084-13). The test temperature was $5^{\circ} \mathrm{C}$ and the stretching speed was $1 \mathrm{~cm} / \mathrm{min} \pm 0.5 \mathrm{~cm} / \mathrm{min}$.

2.3.4. Viscosity Test. Viscosity represents the shear capacity of asphalt at high temperatures. According to the experimental method of the ASTM D4402 (ASTM 2015b) standard, in this paper, viscosity test was executed at the temperature of $135^{\circ} \mathrm{C}$. The testing equipment was the asphalt Brookfield Rotational Viscometer SD-0625 (Shanghai Institute of Geosciences and Technology Institute), where the rotor $21 \#$ was selected.

2.3.5. Dynamic Shear Rheometer (DSR) Test (AASHTO T31509). The dynamic shear rheometer test can measure the viscosity and elastic properties of asphalt mastic at medium and high temperature. In this study, Malvern Bohlin Gemini 200 (British Malvern Instruments Ltd) was utilized to measure the complex modulus $\left(G^{*}\right)$ and the phase angle $(\delta)$, as detailed in the standard of ASTM D7175 (ASTM 2015a). According to the standard ASTM D7175 (ASTM 2015a), the tests were performed by a parallel plate that had a gap of $1.0 \mathrm{~mm}$ and diameter of $25 \mathrm{~mm}$. The asphalt specimen was placed between two parallel plates; the bottom plate was fixed. The upper plate was oscillated at a loading frequency of $10 \mathrm{rad} / \mathrm{s}(1.59 \mathrm{~Hz})$. The complex shear modulus $\left(G^{*}\right)$ and the phase angle $(\delta)$ were measured at $52^{\circ} \mathrm{C}, 58^{\circ} \mathrm{C}, 64^{\circ} \mathrm{C}$, and $70^{\circ} \mathrm{C}$. The Superpave specification utilized the rutting factor $\left(G^{*} / \sin \delta\right)$ as a high temperature evaluation index of the binding material.

2.3.6. Bending Beam Rheometer Test (AASHTO T313-09). The bending beam rheometer tests (BBR) proposed by the SHRP are widely utilized to measure the low temperature creep properties of asphalt mastic. BBR test was developed to measure the stiffness modulus of asphalt mastic and evaluate the corresponding crack resistance [32]. In BBR test, creep stiffness $(S)$ and $m$-value $(m)$ were measured. In accordance with ASTM D6648 (ASTM 2008), in this study, the low temperature creep property of DBFCMAM was measured by the bending rheometer (TE-BBR, Cannon Instrument Company, USA). The test temperature was $-12^{\circ} \mathrm{C}$ and the specimen was formed with an aluminum film of $125 \mathrm{~mm} \times$ $12.5 \mathrm{~mm} \times 6.25 \mathrm{~mm}$ in dimensions.

DBFCMAM was heated to $150^{\circ} \mathrm{C}$ for $3 \mathrm{~h}$, to ensure sufficient liquidity. Following, it was mixed prior to being poured into the mold. The molds filled with the samples were placed on the test bench. Subsequently, the samples were cooled down at room temperature for $60 \mathrm{~min}$; soon afterwards the molds were insulated in the environment at $-5^{\circ} \mathrm{C}$ for $1 \mathrm{~min}$ and demolded. The samples were placed in the test solution at $-12^{\circ} \mathrm{C}$ for $60 \mathrm{~min}$. Following, the samples were placed on two steel supports (span $102 \mathrm{~mm}$ ) and applied a sustained load of $0.98 \mathrm{kN}$ for $240 \mathrm{~s}$. Through the load and the measured central crown the creep stiffness $(S)$ and the creep rate $(m)$ were calculated. The $m$-value represented the stress relaxation ability of DBFCMAM.

The creep stiffness $(S)$ and the creep rate $(m)$ were calculated by (2), when the applied loading duration was $8.0 \mathrm{~s}$, $15.0 \mathrm{~s}, 30.0 \mathrm{~s}, 60.0 \mathrm{~s}, 120.0 \mathrm{~s}$, and $120 \mathrm{~s}$.

$$
\begin{aligned}
\lg S(t) & =A+B \lg (t)+C[\lg (t)]^{2}, \\
m(t) & =|B+2 C \lg (t)| .
\end{aligned}
$$

According to the ASTMD6648 standard, both $S$ and $m$ were determined at a loading duration of $60 \mathrm{~s}$. The creep stiffness $(S)$ was higher and asphalt mastic was harder and quite susceptible to cracking at low temperatures. The higher the creep rate $(m)$ was, the quite improved the stress relaxation capacity was.

\section{Results and Discussion}

3.1. Traditional Asphalt Mastic Test Measurements. The cone depth, the shear stress, the softening point, and the viscosity test results of asphalt mastic are presented in Table 5.

According to the data in Table 5, the cone depth of DBFCMAM apparently decreased, whereas the shear strength significantly increased. The softening point of asphalt mastic following diatomite and basalt fiber addition was increased. The viscosity value of DBFCMAM also was improved with the addition of diatomite and basalt fiber, which indicated that the fluidity of DBFCMAM was reduced at high temperature, but higher viscosity would cause that the mixing temperature and compaction temperature to increase [33]. The diatomite could effectively adsorb the lower molecular group and the lower polar aromatic molecules for the corresponding mesoporous structure [35]; therefore the softening point and viscosity of DBFCMAM were higher compared to the neat asphalt. Xiong et al. [25] indicated that basalt fiber could induce the three-dimensional spatial networking effect. In addition, fibers could absorb the light components of the asphalt and increase the stiffness and viscosity of asphalts [14]. Accordingly, basalt fiber had higher effect on the cone sink depth reduction, improving the shear stress and increasing the softening and viscosity of DBFCMAM.

The cone sink depth reduction and the shear stress increase showed the stiffness of DBFCMAM increase. The increased stiffness indicates a higher rut resistance of the compound modified asphalt master. The softening point and the viscosity increased with the addition of diatomite and basalt fiber. This meant that the modification with diatomite and basalt fiber made the asphalt mastic less susceptible to traffic-induced deformation at high temperatures when compared with neat asphalt mastic. These variations in cone 
TABLE 5: Conventional test results of modified asphalt.

\begin{tabular}{lcccc}
\hline $\begin{array}{l}\text { Modifiers content } \\
(\%)\end{array}$ & Cone depth $(0.1 \mathrm{~mm})$ & $\begin{array}{c}\text { Shear stress } \\
\tau(\mathrm{kPa})\end{array}$ & Softening point $\left({ }^{\circ} \mathrm{C}\right)$ & Viscosity $\left(135^{\circ} \mathrm{C}\right)$ \\
\hline$(0,0)$ & 86.2 & 13.2 & 46.7 & 306.9 \\
$(5,1)$ & 78.1 & 16.1 & 46.9 & 420.4 \\
$(5,2)$ & 70.5 & 19.7 & 47.2 & 413.2 \\
$(5,3)$ & 60.6 & 26.7 & 47.7 & 445.7 \\
$(5,4)$ & 60.4 & 26.9 & 47.8 & 483.2 \\
$(7.5,1)$ & 63.7 & 24.2 & 47.0 & 350.1 \\
$(7.5,2)$ & 61.2 & 26.2 & 47.3 & 386.8 \\
$(7.5,3)$ & 60.1 & 27.3 & 48.1 & 468.3 \\
$(7.5,4)$ & 57.7 & 29.5 & 48.5 & 470.2 \\
$(10,1)$ & 57.8 & 29.4 & 47.7 & 433.5 \\
$(10,2)$ & 57.4 & 29.8 & 47.9 & 455.2 \\
$(10,3)$ & 56.4 & 30.8 & 47.9 & 476.6 \\
$(10,4)$ & 53.8 & 33.9 & 48.0 & 502.7 \\
\hline
\end{tabular}

TABLE 6: Results of force ductility test.

\begin{tabular}{lccc}
\hline Modifiers content $(\%)$ & $F_{\max }(\mathrm{N})$ & $D_{\mathrm{ON}}(\mathrm{mm})$ & $J(\mathrm{~N} \cdot \mathrm{m})$ \\
\hline$(0,0)$ & 78.2 & 388 & 1089.7 \\
$(5,1)$ & 80.1 & 379 & 1367.7 \\
$(5,2)$ & 83.2 & 255 & 1410.3 \\
$(5,3)$ & 112.8 & 225 & 1677.6 \\
$(5,4)$ & 89.4 & 216 & 1463.9 \\
$(7.5,1)$ & 85.1 & 286 & 1205.7 \\
$(7.5,2)$ & 94.4 & 260 & 1529.4 \\
$(7.5,3)$ & 96.8 & 220 & 1739.4 \\
$(7.5,4)$ & 99.1 & 202 & 1578.7 \\
$(10,1)$ & 104.4 & 170 & 1565.6 \\
$(10,2)$ & 91.5 & 131 & 1569.8 \\
$(10,3)$ & 89.9 & 96 & 1519.6 \\
$(10,4)$ & 83.8 & 96 & 1233.0 \\
\hline
\end{tabular}

depth, softening points, and viscosity were beneficial; the high temperature stability of the asphalt mastic with the addition of both diatomite and basalt fiber was enhanced and they were further checked with DSR tests.

3.2. Force Ductility Test. The force ductility test at $5^{\circ} \mathrm{C}$ was employed for the low temperature tensile property evaluation of asphalt mastic. In order for the low temperature performance of asphalt mastic to be quantitatively compared by the addition of diatomite and basalt fiber, $F_{\max }, D_{\mathrm{ON}}$, and $J$ were used for the evaluation index. The force-elongation curves were shown in Figure 2, and the values of $F_{\max }, D_{\mathrm{ON}}$, and $J$ were listed in Table 6.

From the test data the following could be concluded:

$F_{\max }$ of DBFCMAM exceeded the neat asphalt corresponding value. $F_{\max }$ represented the tensile cohesive failure strength of asphalt mastic. It indicated that the tensile cohesive failure strength of DBFCMAM increased; therefore the low temperature tensile strength of DBFCMAM improved. When diatomite and basalt fiber content was $(5 \%, 3 \%)$, the low temperature tensile property of DBFCMAM was the best.

$D_{\mathrm{ON}}$ represents the deformation performance of asphalt mastic. $D_{\mathrm{ON}}$ of DBFCMAM decreased compared to the neat asphalt; it was demonstrated that the low temperature tensile flexibility of DBFCMAM was reduced.

With the inconsistent conclusions obtained from $F_{\max }$ and $D_{\mathrm{ON}}$ consideration, the deformation energy $(J)$ which was a comprehensive indicator was selected to evaluate the low temperature performance of DBFCMAM; $J$ revealed the results of $F_{\max }$ and $D_{\mathrm{ON}}$. $J$ was higher; the tensile resistance of asphalt mastic was better [8]. As presented in Table 6, the tensile property of DBFCMAM was improved. When diatomite and basalt fiber content was $(7.5 \%, 3 \%)$, DBFCMAM had the best low temperature tensile properties.

The results from Table 6 demonstrated that the low temperature performance of DBFCMAM was improved compared to the neat asphalt. When the content of diatomite is constant, as basalt fiber content increased, the low temperature performance increased firstly and consequently decreased. When the diatomite and basalt fiber content was $(7.5 \%, 3 \%)$, the low temperature performance of DBFCMAM was the best. In general, when diatomite and basalt fiber content is different, the low temperature tensile property of asphalt mastic differed, but the low temperature tensile property of DBFMCAM is improved.

3.3. Dynamic Shear Rheological (DSR) Test. The dynamic shear rheological (DSR) test was utilized to measure the viscoelasticity of asphalt mastic at medium and high temperature. The main viscoelastic parameters of the asphalt mastic are the complex shear modulus $\left(G^{*}\right)$ and the phase angle $(\delta) . G^{*}$ was used to evaluate the antirutting ability of asphalt mastic. The phase angle $(\delta)$ represented the time lag between the applied shear stress and the resulting shear strain [32]. 

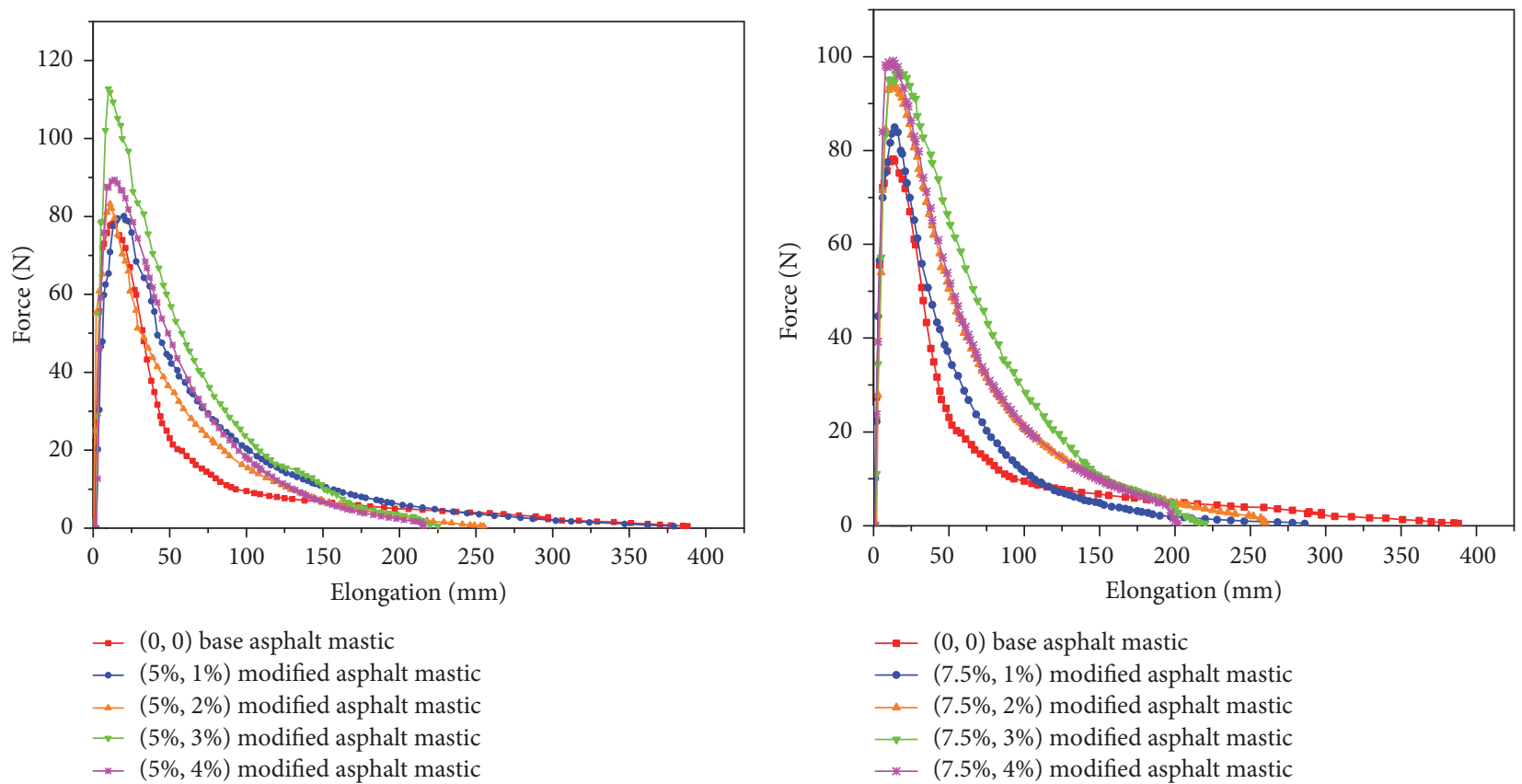

(b)

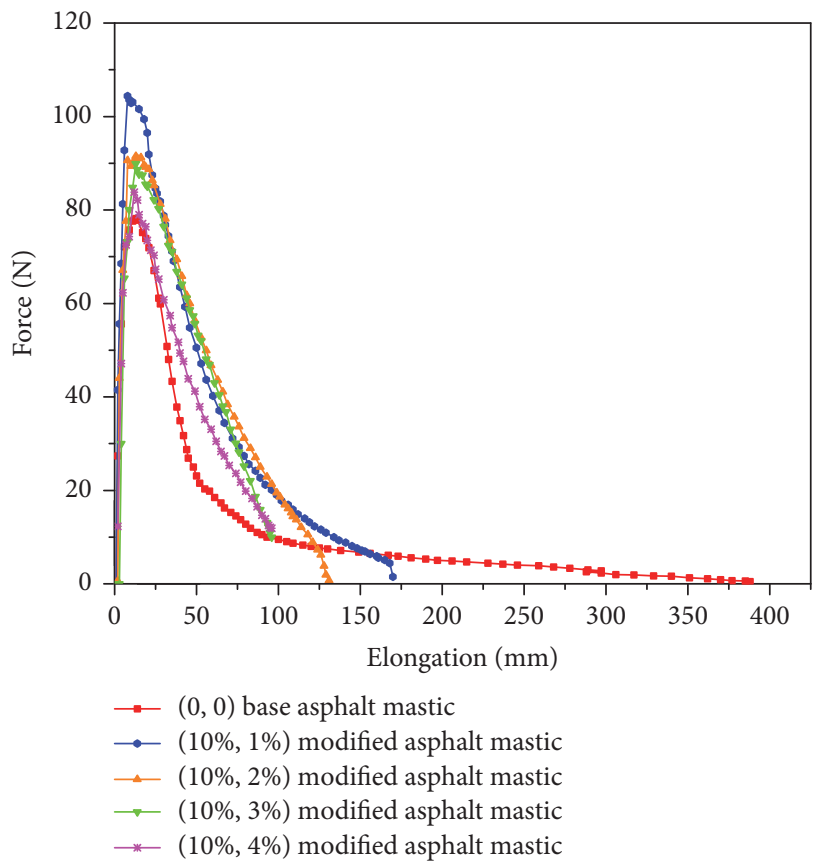

(c)

FIGURE 2: FDT force-elongation curves of asphalt mastics.

When the phase angle $(\delta)$ was zero, asphalt mastic was a pure elastic material, whereas when $\delta$ was $90^{\circ}$, asphalt mastic was a purely viscous material. Under high temperature, the phase angle reduction of asphalt mastic could enhance the elasticity. The higher the $G^{*}$ value was, the greater the stiffness was and thus the more resistant to rutting the asphalt mastic would be. The lower the phase angle $(\delta)$, the more elastic the binder $[36,37]$.
In this paper the DSR test was conducted to compare the difference of rheological property between different asphalt mastics. The complex modulus $\left(G^{*}\right)$ and phase angle $(\delta)$ at certain temperature $\left(52^{\circ} \mathrm{C}, 58^{\circ} \mathrm{C}, 64^{\circ} \mathrm{C}\right.$, and $\left.70^{\circ} \mathrm{C}\right)$ and particular frequency (10 rad/s) were obtained, which could be considered that the shear rheological properties of different asphalt mastics could be compared and analyzed according to references $[8,10,28]$. 
TABLE 7: Result of DSR test.

\begin{tabular}{lcccccccc}
\hline $\begin{array}{l}\text { Content } \\
(\%)\end{array}$ & \multicolumn{3}{c}{$G^{*}(\mathrm{kPa})$} & & \multicolumn{3}{c}{$\delta\left(^{\circ}\right)$} \\
\hline$(0,0)$ & $52^{\circ} \mathrm{C}$ & $58^{\circ} \mathrm{C}$ & $64^{\circ} \mathrm{C}$ & $70^{\circ} \mathrm{C}$ & $52^{\circ} \mathrm{C}$ & $58^{\circ} \mathrm{C}$ & $64^{\circ} \mathrm{C}$ & $70^{\circ} \mathrm{C}$ \\
$(5,1)$ & 24.081 & 13.101 & 6.8281 & 2.4404 & 82.89 & 84.39 & 85.94 & 87.01 \\
$(5,2)$ & 30.901 & 16.881 & 8.77603 & 3.0117 & 80.9 & 83.27 & 84.89 & 86.53 \\
$(5,3)$ & 32.701 & 18.28 & 9.9429 & 3.4755 & 79.7 & 82.71 & 84.58 & 86.03 \\
$(5,4)$ & 37.6 & 19.191 & 10.5278 & 3.7996 & 78.22 & 82.28 & 84.16 & 85.77 \\
$(7.5,1)$ & 38.703 & 20.833 & 11.1901 & 3.9362 & 77.7 & 81.94 & 83.86 & 85.51 \\
$(7.5,2)$ & 36.502 & 18.512 & 8.7614 & 2.9204 & 78.94 & 82.84 & 84.06 & 86.1 \\
$(7.5,3)$ & 39.457 & 22.642 & 9.8548 & 3.4952 & 77.68 & 82.19 & 83.65 & 85.86 \\
$(7.5,4)$ & 42.505 & 23.117 & 10.8593 & 3.8334 & 76.25 & 81.72 & 83.39 & 85.68 \\
$(10,1)$ & 43.391 & 24.164 & 11.8563 & 4.1401 & 75.15 & 81.26 & 83.01 & 85.21 \\
$(10,2)$ & 39.731 & 21.753 & 9.1982 & 3.2764 & 77.78 & 82.24 & 83.82 & 86.05 \\
$(10,3)$ & 42.302 & 23.978 & 10.3312 & 3.5965 & 76.6 & 81.82 & 83.47 & 85.76 \\
$(10,4)$ & 43.833 & 24.845 & 11.2616 & 3.9881 & 75.91 & 81.42 & 83.15 & 85.51 \\
\hline
\end{tabular}

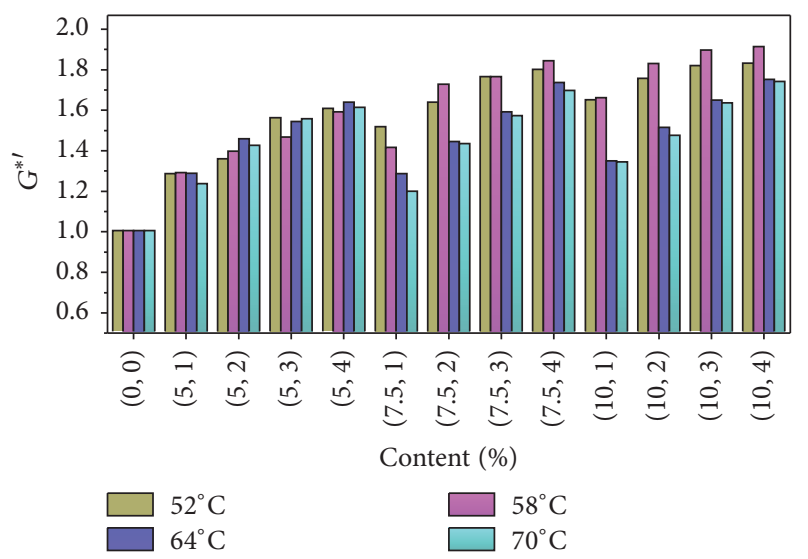

Figure 3: $G^{* \prime}$ change trend graph.

The experimental data was listed in Table 7. Asphalt was a typical viscoelastic material, which presents small complex modulus at high temperature and large one at low temperature. In order to compare the change trend of $G^{*}, \delta$, and $G^{*} / \sin \delta$ with different content at different temperatures, the results $\left(G^{*}, \delta\right.$, and $\left.G^{*} / \sin \delta\right)$ were normalized treatment and then showed in Figures 3-5. Equation (3) was used for normalization.

$$
y^{\prime}=\frac{y_{(i, j)}}{y_{(0,0)}},
$$

$y^{\prime}$ is normalized parameter, $y_{(i, j)}$ is the parameter of DBFCMAM, $y_{(0,0)}$ is the parameter of the neat asphalt, $i=5 \%, 7.5 \%$, and $10 \%$ (content of diatomite), and $j=1 \%, 2 \%, 3 \%$, and $4 \%$ (content of basalt fiber).

It could be observed from the complex shear modulus trend graph (Figure 3) that all the complex shear moduli of DBFCMAM were higher than the neat asphalt. The complex shear modulus $\left(G^{*}\right)$ was decreased by increasing the test temperature. At the same temperature, when the diatomite

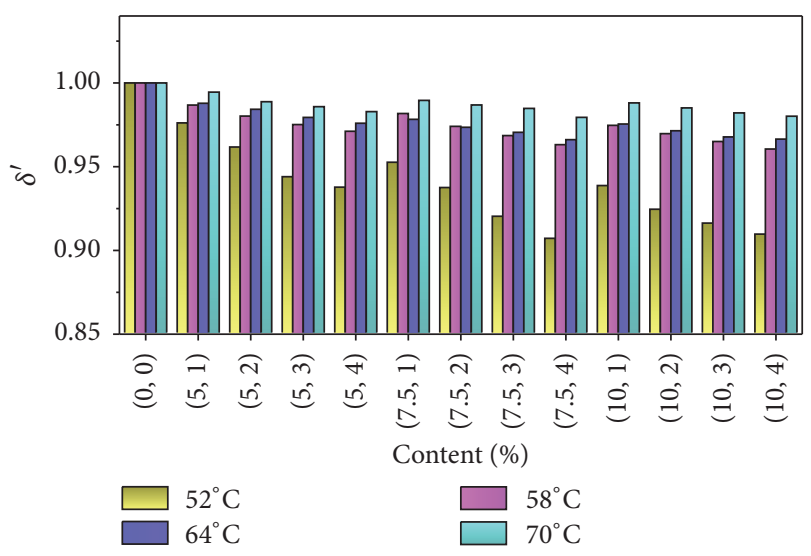

FIGURE 4: $\delta^{\prime}$ change trend graph.

content was constant, the increment of $G^{*}$ was gradually greater as basalt fiber content increased.

According to Figure 4, it could be observed that the phase angle $(\delta)$ of DBFCMAM changed trend and the phase angle $(\delta)$ of DBFCMAM decreased comparing to the neat asphalt, whereas the reduction was decreased as the test temperature rose; it indicated that the viscosity of the asphalt mastic varied slightly as the temperature increased. At the same temperature, when the diatomite content was constant, the reduction of $\delta$ was gradually greater as basalt fiber content increased.

The increase $G^{*}$ and decrease phase angle $\delta$ indicate that addition of diatomite and basalt fibers to asphalt mastic reduces the thermal susceptibility of DBFCMAM. Thus the DBFCMAM would be more capable of recovering its original shape after being subjected to loads. The increase in the $G^{*}$ and decrease in the $\delta$ demonstrated that the stiffness of the asphalt mastic were enhanced by the use of diatomite and basalt fibers, which meant increased resistance to rutting at higher temperatures.

The rutting factor $\left(G^{*} / \sin \delta\right)$ is a measure of high temperature resistance stiffness or rutting resistance of asphalt 


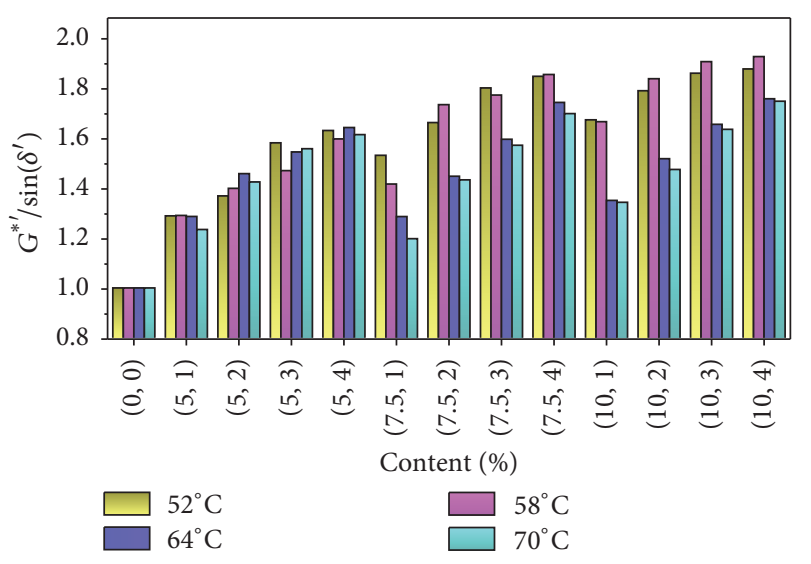

FIGURE 5: $G^{* \prime} / \sin \delta^{\prime}$ change trend graph.

mastic and regularly utilized to describe the rutting resistance at high temperatures [38]. The Superpave technique requires $G^{*} / \sin \delta>1.0 \mathrm{kPa}$ for asphalt mastic sample $[39,40]$. The higher the $G^{*} / \sin \delta$ was, the better the rutting resistance property of asphalt pavement was [41]. From Figure 5, the $G^{*} / \sin \delta$ values of DBFCMAM were higher than that of the neat asphalt. At the same temperature, when the diatomite content was constant, the increment of $G^{*} / \sin \delta$ was gradually greater as basalt fiber content increased, which might be attributed to the good distribution of fibers in different directions in asphalt mastic which resisted the shear displacements and improved the shear resistance of the asphalt from the external forces [42]. As the temperature increased, the increment of $G^{*} / \sin \delta$ gradually decreased. Asphalt mastic resistance to rutting weakened at high temperature, but the rutting resistance was improved by addition of diatomite and basalt fiber. All rutting factors exceeded $1.0 \mathrm{kPa}$ at $70^{\circ} \mathrm{C}$, so the antirutting ability of DBFCMAM satisfied Superpave's requirement.

These parameters showed that diatomite and basalt fiber could offer better rutting resistance at high service temperature.

3.4. Bending Beam Rheometer (BBR) Test. The creep stiffness $S$ and the creep rate (slope) $m$ of DBFCMAM were determined under different temperature by the bending beam rheometer (BBR) in SHRP of US. SHRP generally requires $S_{(t=60 \mathrm{~s})} \leq 300 \mathrm{MPa}, m \geq 0.3$ [26]. The smaller $S$ was, the better the cryogenic flexibility and nondeformability of modified asphalt mastic are; $m$ was higher, the asphalt creep stiffness $S$ was lower, the cryogenic stress relaxation ability of asphalt mastic was better, and the low temperature performance was better. With the data obtained from BBR test, the low temperature performance of various contents of DBFCMAM could be evaluated. Taking the average of three parallel tests, the results under the low temperature $\left(-12^{\circ} \mathrm{C}\right)$ were presented in Figures 6 and 7.

According to Figure 6, when the content of basalt fiber was constant, as the diatomite content increased and $S$ increased. If the content of diatomite was constant, basalt fiber content increased, and that leads to $S$ increase. There as the content of diatomite and basalt fiber increased, $S$
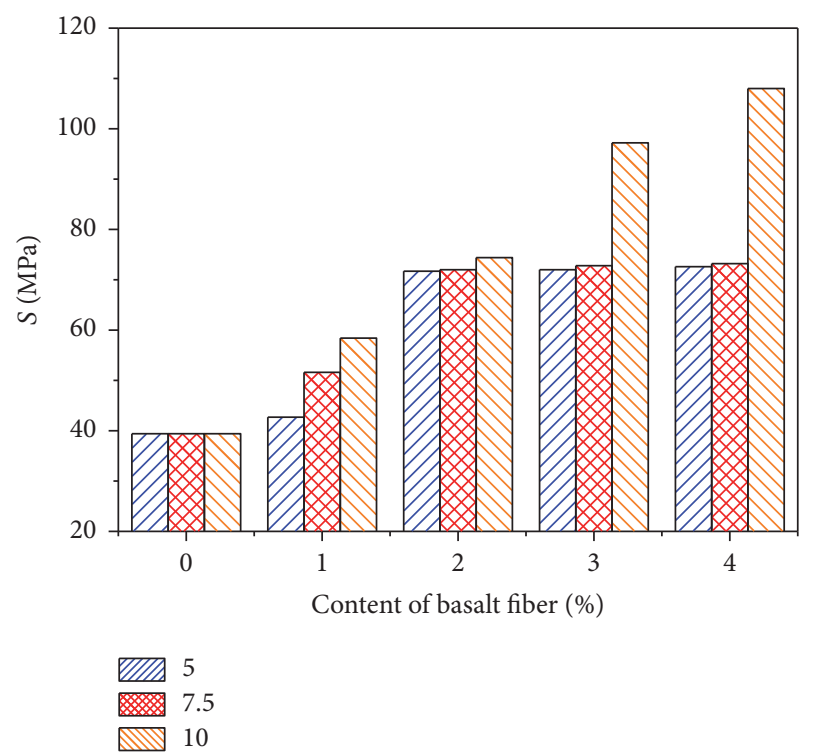

FIgURE 6: $S$ of asphalt mastics versus content.

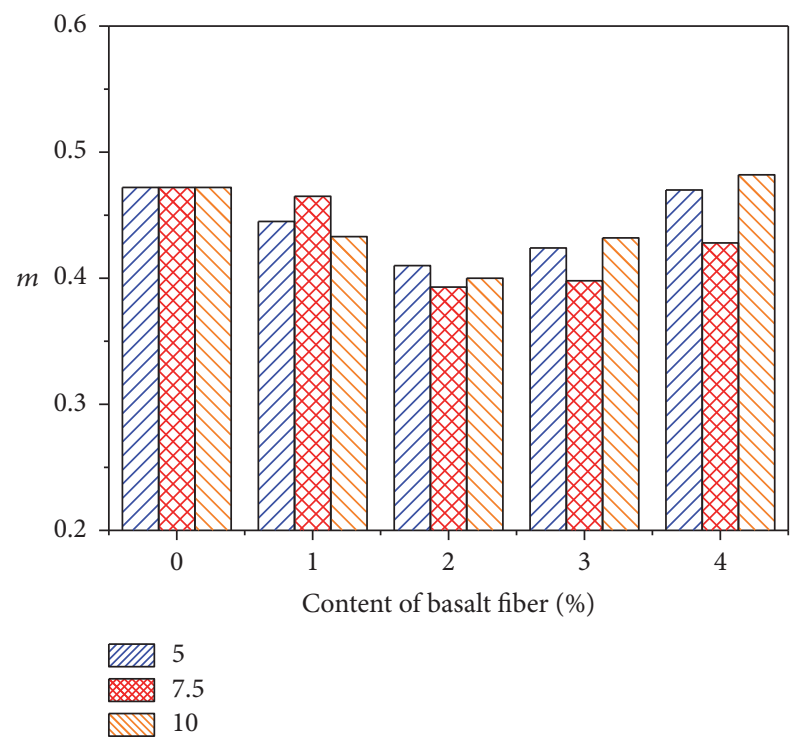

FIGURE 7: $m$ of asphalt mastics versus content.

increased. The $S$ values of DBFCMAM were higher compared to the neat asphalt. When the content was $(5 \%, 1 \%), S$ was similar to the neat asphalt. According to Figure 7, the $m$ values were lower than the neat asphalt. The $m$ value decreased firstly and then increased, as the diatomite and basalt fiber content increased.

The low temperature creep stiffness $S$ of DBFCMAM was larger than that of neat asphalt, indicating that where diatomite and basalt fiber were added, the viscosity and stiffness of asphalt mastic increased, whereas the toughness decreased and the stress relaxation ability weakened. So the low temperature performance of DBFCMAM declined. At $-12^{\circ} \mathrm{C}, S$ was below $300 \mathrm{Mpa}, m$-value exceeded 0.3 , within the scope of SHRP requirements; therefore DBFCMAM met the low temperature performance requirements at $-12^{\circ} \mathrm{C}$. 
The data of the BBR test indicated that the addition of diatomite and basalt fiber did not improve the low temperature performance of asphalt mastic. The conclusion was inconsistent with the force ductility. The inconsistent conclusions of BBR test and force ductility test were caused by the differential test conditions and test mechanism of the two tests. In the BBR test the values of flexural stress and flexural strain were obtained and used to calculate creep stiffness $S(t)$ and creep rate (slope) $m$. The deformations of specimens were very low at the end of BBR test. It could not reflect the crosslinking effect of basalt fiber. And the creep stiffness $S$ was improved for the absorbing effect of diatomite. However, in the force ductility test, the specimens reached its ultimate damage; the basalt fibers played a reinforcing role. Thus, the BBR test was probably not suitable to evaluate the low temperature performance of DBFCMAM.

Liu et al. [26] concluded that the stiffness of basalt fiber asphalt was smaller than that of neat asphalt while the $m$ value was higher than that of neat asphalt at $-10^{\circ} \mathrm{C}$. Cryogenic property of asphalt was improved by the basalt fiber at that temperature. However, the basalt fiber weakened the cryogenic property of asphalt at $-20^{\circ} \mathrm{C}$ according to results of BBR test, whereas the fiber could improve the cryogenic anticracking properties of the asphalt mixture.

In this paper the conclusion of BBR test at $-12^{\circ} \mathrm{C}$ was not in agreement with the previous study done by Liu et al. at $-10^{\circ} \mathrm{C}$. There might be two reasons why BBR result was not in good agreement with Liu et al. The first one was different test temperature. The other one was the different modifiers (i.e., basalt fiber in Liu's study, diatomite and basalt fiber in this paper). The reference $[16,43]$ had suggested that the cryogenic creep stiffness of diatomite modified asphalt mastic is higher, which leads to the cryogenic performance of asphalt decreasing. So the conclusion of this paper is not completely consistent with that by Liu et al. However, in this paper the force ductility test conclusion was consistent with the conclusion of Liu et al. that the cryogenic anticracking property of the asphalt mixture was improved. So we recommend that the force ductility test was more reliable to evaluate the low temperature tensile properties of DBFCMAM.

\section{Conclusions}

In this paper, the properties of diatomite and basalt fiber compound modified asphalt mastic were investigated; through laboratory experiments the following conclusions could be drawn.

(1) According to the cone penetration test, the softening point test, and the viscosity test, cone depth was reduced, whereas shear stress, softening point, and viscosity were increased, when diatomite and basalt fiber were added to asphalt mastic. Hence the diatomite and basalt fiber compound asphalt (DBFCMAM) had better resistance to rutting at high temperature compared to the neat asphalt; the high temperature stability of asphalt mastic was improved by diatomite and basalt fiber.

(2) The DSR test demonstrated that following diatomite and basalt fiber addition, complex shear modulus $G^{*}$ and rutting factor $\left(G^{*} / \sin \delta\right)$ increased and the phase angle $(\delta)$ decreased. The addition of diatomite and basalt fiber significantly improved stiffness and elasticity of the asphalt mastic; therefore the high temperature performance of DBFCMAM displayed a sharp increase compared to neat asphalt.

(3) The low temperature performance of asphalt mastic was improved by the addition of diatomite and basalt fiber according to the results of the force ductility test. The BBR test was considered not suitable to evaluate the low temperature performance of DBFCMAM because the BBR test could not reflect the cross-linking effect of basalt fiber.

\section{Conflicts of Interest}

The authors declare that there are no conflicts of interest regarding the publication of this paper.

\section{Acknowledgments}

The authors express their appreciation for the financial supports of the National Natural Science Foundation of China under Grant nos. 51678271, 51508150, and 51408258, Science Technology Development Program of Jilin Province (20160204008SF), and Transportation Science \& Technology Project of Jilin Province (2015-1-13).

\section{References}

[1] G. King, "Additives in asphalt," Journal of the Association of Asphalt Paving Technologisists, vol. 68, pp. 32-69, 1999.

[2] B. Guan, R. Xiong, and R. He, "Investigation of usability of brucite fiber in asphalt mixture," International Journal of Pavement Research and Technology, vol. 7, no. 3, pp. 193-202, 2014.

[3] X. J. Deng, Subgrade and Pavement Engineering, China Communications Press, Beijing, China, 2004 (Chinese).

[4] Y. R. Kim, Modeling of Asphalt Concrete, McGraw-Hill, New York, NY, USA, 2009.

[5] C. Giavarini, P. De Filippis, M. L. Santarelli, and M. Scarsella, "Production of stable polypropylene-modified bitumens," Fuel, vol. 75, no. 6, pp. 681-686, 1996.

[6] H. Yao, Z. You, L. Li et al., "Performance of asphalt binder blended with non-modified and polymer-modified nanoclay," Construction and Building Materials, vol. 35, pp. 159-170, 2012.

[7] Y. Cheng, J. Tao, Y. Jiao, Q. Guo, and C. Li, "Influence of diatomite and mineral powder on thermal oxidative ageing properties of asphalt," Advances in Materials Science and Engineering, vol. 2015, Article ID 947834, 10 pages, 2015.

[8] Y. Cheng, J. Tao, Y. Jiao et al., "Influence of the properties of filler on high and medium temperature performances of asphalt mastic," Construction and Building Materials, vol. 118, pp. 268275,2016

[9] P. Cong, N. Liu, Y. Tian, and Y. Zhang, "Effects of long-term aging on the properties of asphalt binder containing diatoms," Construction and Building Materials, vol. 123, pp. 534-540, 2016.

[10] G. G. Al-Khateeb and K. Z. Ramadan, "Investigation of the effect of rubber on rheological properties of asphalt binders using superpave DSR," KSCE Journal of Civil Engineering, vol. 19, no. 1, pp. 127-135, 2015.

[11] K. H. Moon, A. C. Falchetto, J. Y. Park, and J. H. Jeong, "Development of high performance asphalt mastic using fine 
taconite filler," KSCE Journal of Civil Engineering, vol. 18, no. 6, pp. 1679-1687, 2014.

[12] D. Wang, L. Wang, X. Gu, and G. Zhou, "Effect of basalt fiber on the asphalt binder and mastic at low temperature," Journal of Materials in Civil Engineering, vol. 25, no. 3, pp. 355-364, 2013.

[13] X. Gu, T. Xu, and F. Ni, "Rheological behavior of basalt fiber reinforced asphalt mastic," Journal Wuhan University of Technology, Materials Science Edition, vol. 29, no. 5, pp. 950-955, 2014.

[14] H. Chen and Q. Xu, "Experimental study of fibers in stabilizing and reinforcing asphalt binder," Fuel, vol. 89, no. 7, pp. 16161622, 2010.

[15] Q. Guo, L. Li, Y. Cheng, Y. Jiao, and C. Xu, "Laboratory evaluation on performance of diatomite and glass fiber compound modified asphalt mixture," Materials \& Design, vol. 66, pp. 5159, 2015.

[16] P. Cong, S. Chen, and H. Chen, "Effects of diatomite on the properties of asphalt binder," Construction and Building Materials, vol. 30, pp. 495-499, 2012.

[17] Y. N. Bao, Study of asphalt mixture modified by diatomite [Master dissertation], Chang'an University, Xi'an, China, 2005 (Chinese).

[18] Y. D. Wang, Research on the anti-ageing mechanism and mechanical properties of diatomite modified asphalt binder [Master's thesis], Jilin University, Changchun, China, 2015 (Chinese).

[19] J. Li, P. W. Hao, and Q. B. Mei, "A study on the performance of diatomite modified asphalt and the mixture," Petroleum Asphalt, vol. 26, pp. 16-18, 2003 (Chinese).

[20] D.-P. Zhu, J.-Z. Zhang, J.-B. Chen, K. Yuan, and C. Cheng, "Experiment on road performance of diatomite modified asphalt mixture in permafrost regions," China Journal of Highway and Transport, vol. 26, no. 4, pp. 23-28, 2013.

[21] $\mathrm{T}$. Xu, Research on performance and mechanism of basalt fibers series reinforced asphalt concrete [Master's thesis], Southeast University, Nanjing, China, 2011.

[22] C. Rong, Y. E. Jun, W. U. Feng-Chun et al., "Investigation on fatigue properties of short-cut basalt fiber asphalt mixture," Highway, no. 11, pp. 188-191, 2013 (Chinese).

[23] N. Morova, "Investigation of usability of basalt fibers in hot mix asphalt concrete," Construction and Building Materials, vol. 47, pp. 175-180, 2013.

[24] Y. Zheng, Y. Cai, G. Zhang, and H. Fang, "Fatigue property of basalt fiber-modified asphalt mixture under complicated environment," Journal Wuhan University of Technology, Materials Science Edition, vol. 29, no. 5, pp. 996-1004, 2014.

[25] R. Xiong, J. Fang, A. Xu, B. Guan, and Z. Liu, "Laboratory investigation on the brucite fiber reinforced asphalt binder and asphalt concrete," Construction and Building Materials, vol. 83, pp. 44-52, 2015.

[26] K. Liu, W. Zhang, and F. Wang, "Research on cryogenic properties of different fiber asphalts and mixtures," Advanced Materials Research, vol. 146-147, pp. 238-242, 2011.

[27] H. Yao, Z. You, L. Li et al., "Evaluation of asphalt blended with low percentage of carbon micro-fiber and nanoclay," Journal of Testing \& Evaluation, vol. 41, no. 2, pp. 278-288, 2013.

[28] L. Yao, Y. Hu, Q. Ma, and X. Ma, "Stability of asphalt binder and asphalt mixture modified by polyacrylonitrile fibers," Advanced Materials Research, vol. 228-229, pp. 242-247, 2011.

[29] D. A. Anderson and T. W. Kennedy, "Development of SHRP binder specifications," Journal of Proceedings of the Association of Asphalt Paving Technologists, vol. 62, no. 93, pp. 481-507, 1993.
[30] T. Hoare and S. Hesp, "Low-temperature fracture testing of asphalt binders: regular and modified systems," in Proceedings of the Transportation Research Board 79th Annual Meeting, pp. 36-42, Transportation Research Board, Washington, DC, USA, 2000.

[31] Y. Edwards, Y. Tasdemir, and U. Isacsson, "Rheological effects of commercial waxes and polyphosphoric acid in bitumen 160/220-low temperature performance," Fuel, vol. 85, no. 7-8, pp. 989-997, 2006.

[32] Y. Yildirim, "Polymer modified asphalt binders," Construction and Building Materials, vol. 21, no. 1, pp. 66-72, 2007.

[33] BS, "Bitumen and Bituminous Binders-Determination of the Tensile Properties of Modified Bitumen by The Force Ductility Method, BS EN 13589:2008, European Committee for Standardization, Brussels, Belgium, 2008.

[34] BS, "Bitumen and Bituminous Binders-Determination of Deformation Energy," BS EN 13703:2004, European Committee for Standardization, Brussels, Belgium, 2004.

[35] Y. Song, J. Che, and Y. Zhang, "The interacting rule of diatomite and asphalt groups," Petroleum Science and Technology, vol. 29, no. 3, pp. 254-259, 2011.

[36] Y. Ruan, R. R. Davison, and C. J. Glover, “The effect of long-term oxidation on the rheological properties of polymer modified asphalts," Fuel, vol. 82, no. 14, pp. 1763-1773, 2003.

[37] S. Wu, Z. Chen, Q. Ye, and W. Liao, "Effects of fibre additive on the high temperature property of asphalt binder," Journal Wuhan University of Technology, Materials Science Edition, vol. 21, no. 1, pp. 118-120, 2006.

[38] W. Uddin, "Viscoelastic characterization of polymer-modified asphalt binders of pavement applications," Applied Rheology, vol. 13, no. 4, pp. 191-199, 2003.

[39] G. D. Airey, "Rheological properties of styrene butadiene styrene polymer modified road bitumens," Fuel, vol. 82, no. 14, pp. 1709-1719, 2003.

[40] R. B. Mcgennis, S. Shuler, and H. U. Bahia, "Background of Superpave asphalt binder test methods," Manuals, 1994.

[41] A. Khadivar and A. Kavussi, "Rheological characteristics of SBR and NR polymer modified bitumen emulsions at average pavement temperatures," Construction and Building Materials, vol. 47, pp. 1099-1105, 2013.

[42] P. M. Kathari, "Rheological Properties of Polypropylene Reinforced Asphalt Binder," Transportation Infrastructure Geotechnology, vol. 3, no. 3-4, pp. 109-126, 2016.

[43] Y. Zhang, H. Zhu, G. Wang, and T. Chen, "Evaluation of low temperature performance for diatomite modified asphalt mixture," Advanced Materials Research, vol. 413, pp. 246-251, 2012. 

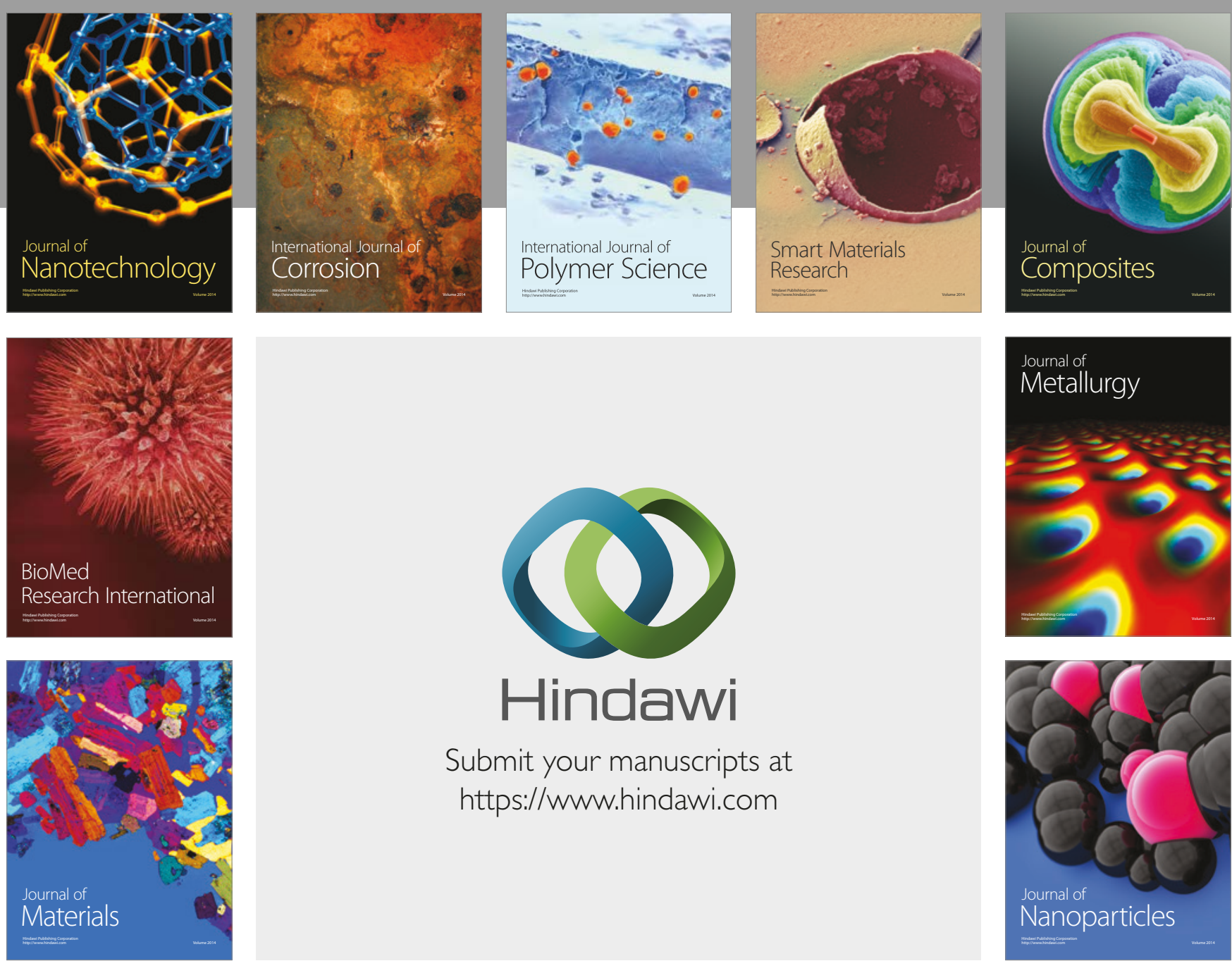

\section{Hindawi}

Submit your manuscripts at

https://www.hindawi.com
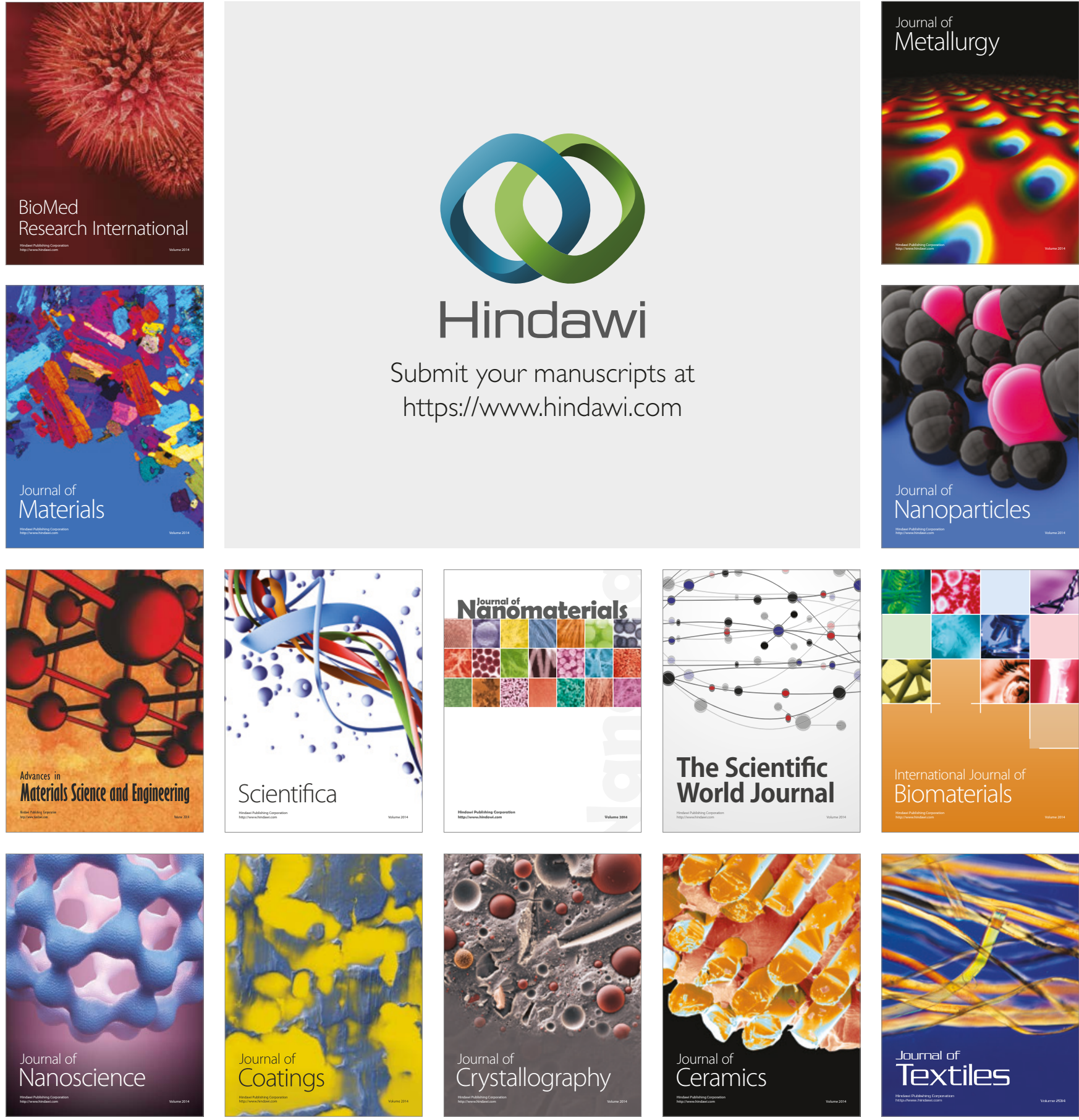

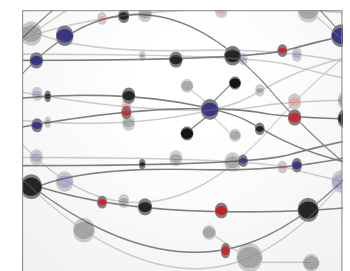

The Scientific World Journal
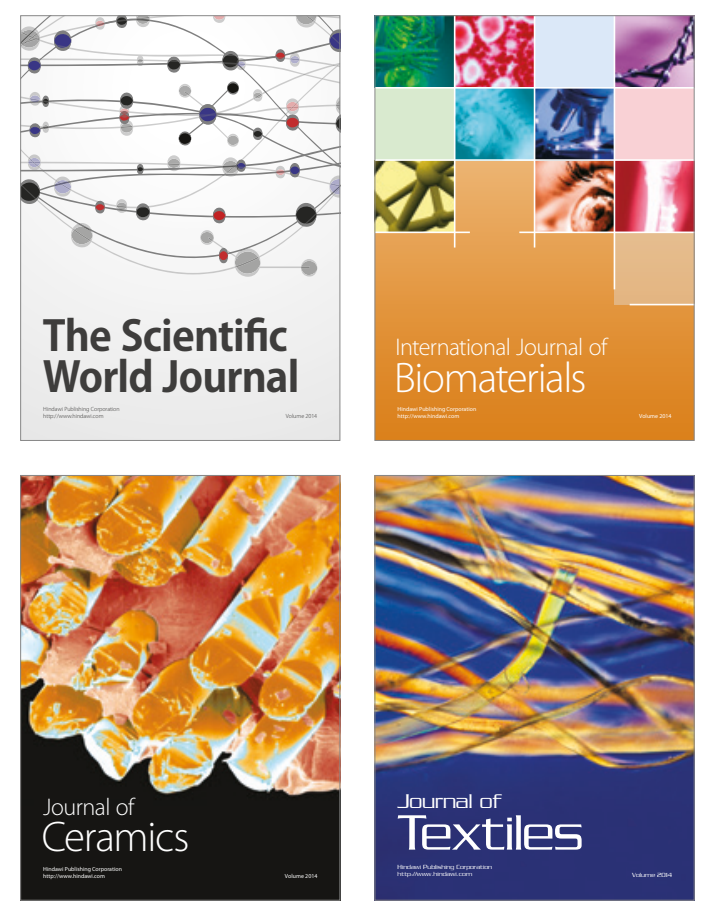